\title{
A Continuable Political Administration System for World Countries (II)
}

\author{
Refet Ramiz \\ Near East University, North Nicosia, North Cyprus, TRNC, Cyprus
}

\begin{abstract}
In this work, some important parts of the system, and the relation between the parts, and its connections with other systems are defined, explained briefly. With this respect, the nature of the person is defined with related parts. A new science branch called "information science" is defined. Importance of the political organizing of a political party is shortly explained. The necessity of the academies for public sector, private sector, and for political administration system is expressed. How to choose a person and how a person can be choose for any part of the system is defined. For both cases "good and/or correct" system criterions, determination of the criterions, and evaluation criterions are defined. New evaluation levels are defined based on the 8-basic senses in philosophical point of view to deepen the sensitivity of the evaluations. The importance of the situation notice and how to make it for each of the association are explained. The 10 main service parameters are defined to show the interactive relations between the ideology, services, person nature and others. Present and possible future problems of a country are expressed. Aims/targets are characterized with real approach for all related sides. Other systems which proposed to be connected to continuable political administration system are shortly defined and expressed. Way of system administration and administration types are shortly explained. The importance and ways of the decision making are expressed. The general ways, types of inspection are shortly explained. Official units that could be assign for the new system are defined. The importance of these units and of the persons that could be assign for these units are expressed together with the definition of the characteristics of the persons or groups that could be. The necessity of an action planning, possible supply and demand cases are defined scientifically. The importance and necessity of sense of justice is explained to make system continuable. The methods of determination of the policies/strategies are expressed.
\end{abstract}

Keywords: administration and systems, philosophy of politics, administration and politics, administration and science, administration and justice, political systems

\section{Introduction}

In the first article (Ramiz, 2015), it is stated that all the political/non-political ideologies (Political Ideologies, 2015; Political spectrum, 2015), 168 religions/beliefs/sects (List of Religions, 2015; Religion, 2015), nearly 1,600 ethnic origin groups (Ethnic Groups, 2015) are synthesized to define continuable political construction. It is found that all the past federations, confederations, empires, ideologies (Ideology, 2015), political administration systems (Political Systems, 2015), thoughts and senses, doctrines, etc. are in fact each

Refet Ramiz, Assist. Professor, Department of Electrical and Electronic Eng.; Department of Political Science; Department of International Relations, Near East University. 
reflects a special functional processes within a general system of where the "kinds of services", "subjects of services", "way of services", "service types" and "persons" are considered and placed as a factor in it and where these factors are arranged through different priorities, weights, and also taken under record with some rules. It is evaluated that each groups, communities, societies, countries are separate models, but at the same time each of them are factors which owns different starting points to reach a correct country structure with five new separate groups: New Era Group, Progression of The Country Group, Unity of The Country Group, Values of The Country Group, and Social Progression Group. The continuable political administration system is defined here by considering the all possible parts and by considering the other systems connected for a country. Possible forceful factors, which can effect political system administration are given. To realize political construction, some political construction methods are defined: (1) Political construction by putting together the values; (2) political construction based on different value; (3) Political construction based on the new defined values; (4) Political construction which considers stepped transition; and (5) Ideal political construction which will carry the political points of views and other standards of judgment, points of views of persons to a same line, are expressed. New ideologies are put forwarded and ideal political construction for a world country is given with details. Integration of the political groups, political ideologies to the new system is explained. Some methods of politics are mentioned. Persons related with politics are classified simply.

Although the first article defines four important parts of the continuable political administration system for a world country, this work includes 17 other important parts of the system which shapes, re-construct the political system, power authorities, and other important parts that should be in the new system. With this respect, this article is complementary to the first article in some manner, and the subjects should be evaluated together for better understanding the sensitivity in design and the importance of the synthesis considered.

Although a block diagram for continuable political administration system for the world countries and its some parts are defined in the first article before, to guide people to evaluate the system parts easily, it is given here again first (see Figure 1), than the other parts of the system are explained. The dark (gray) blocks used to express that these blocks are defined in the first article. Some of the references are given in the first article, and they are considered for the general synthesis where the results of this synthesis also given here in this work. Some other references are given here as additional sources to guide the people to understand the meaning of the some words, definitions used here, and for making comparison easily between the past, present and new theory, new system.

\section{Political Administration System for a Country}

\section{General Structure of the System}

In general a political administration system for a country is given in Figure 1) below with 21 blocks. Four parts of this system explained before, and 17 other parts explained here new, beside making additions to the one old part first.

\section{Persons Related with the Politics}

As an addition to the information given about the persons related with politics in the first article (Ramiz, 2015), here it is important to consider the following cases about the politics or politicians additionally: (1) Status of Politic person: Politicians who can affect the political administration directly or indirectly, could probably have the following status together or separately: politics due to his/her education status, politic expert 
due to education subject, politic expert due to subject of service, politic expert due to way of service, politics expert due to method of politics, or politic expert in other subject; (2) Ethics of Politic person: in general it is a factor within the system, which can measured by the following parameters: information science, preference types, relations with other people, personal character, personal way of expression, person's way of approach to a subject (optimist, pessimist, hybrid cases due to subjects), education, political language using, social values, status, political construction, other.

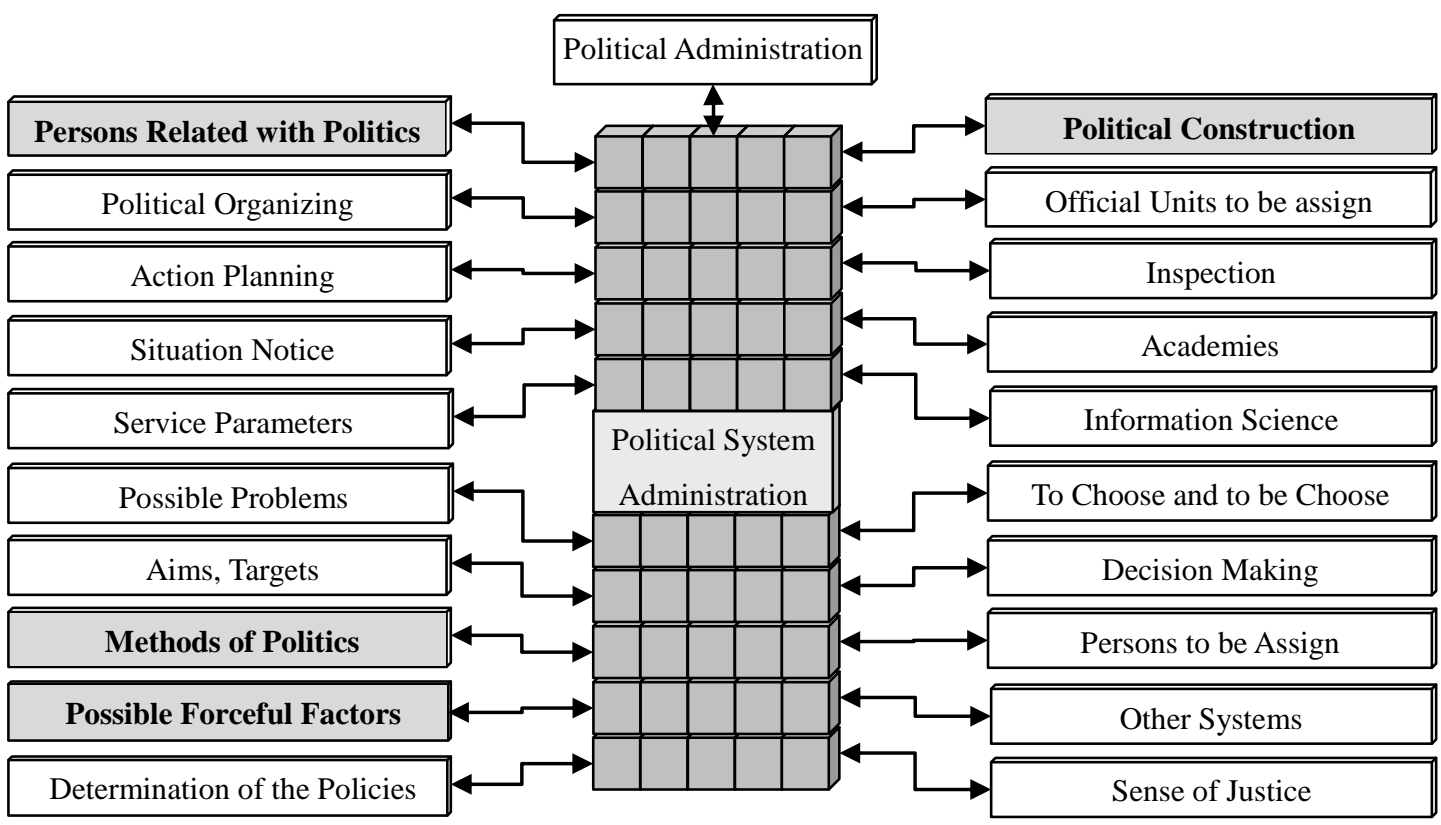

Figure 1. General structure of the political administration system for a country.

Another important specific parameter is "person", and defined generally with his/her nature as in Figure 2 below. It is possible to evaluate each of the factors effective on a person nature separately or all of his/her nature together. Here, the relations of a person and the characteristics of mind are generally expressed in Figure 3 and Figure 4 below.

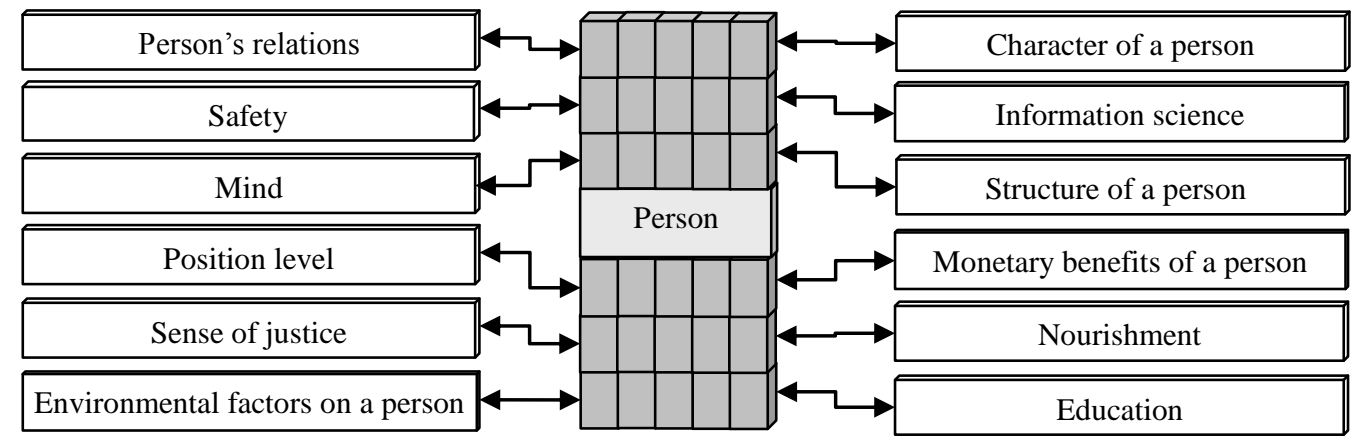

Figure 2. Person's nature.

\section{Information Science}

Information science is defined as a scientific point of view, and as a necessity of the system mentioned here, where the plans and principles related with the all subjects of services are teaching, educating, and making 
applicable under the following principles: (1) information forming; (2) information protection; (3) information acquiring; (4) information presenting; (5) information directing; and (6) information inspection. Information science also supply the formation of the following abilities, and their progression for persons and administration: (a) regarding the person: wisdom, leadership, to establish a relation, ability to make preference, ability of administration, respect, other; (b) regarding a person and administration: trust, devotion, respect, honesty between person(s) and administration; (c) regarding the administration: ability to direct, ability to make preference, other. Information science is important: (i) together with the functional power levels; and (ii) together with the functional position levels. The functional power levels proposed due to the abilities of using "information", "infrastructure", "fiscal power", and "military power" separately or together as hybrid-cases. There are 17 functional power levels defined for these four factors, which can show the possible real effects of a person, or group, or country in the system generally. Here, it is expressed that "information" is a necessary factor to start a work and this is the lowest level functional power. As it can be realized from the related figures, the information is related with the person's nature, so person's relation and mind in general/specific manner.

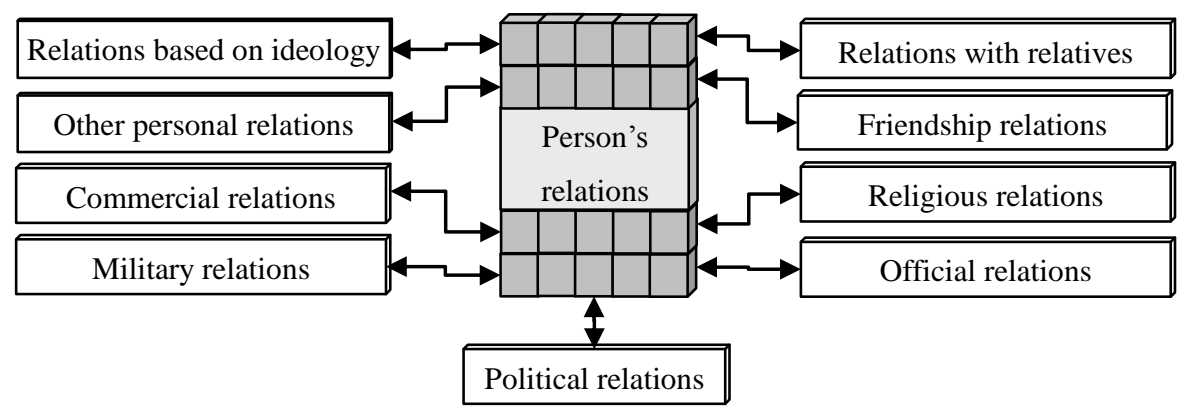

Figure 3. Person's relations.

The mind proposed to have some parts as in Figure 4.

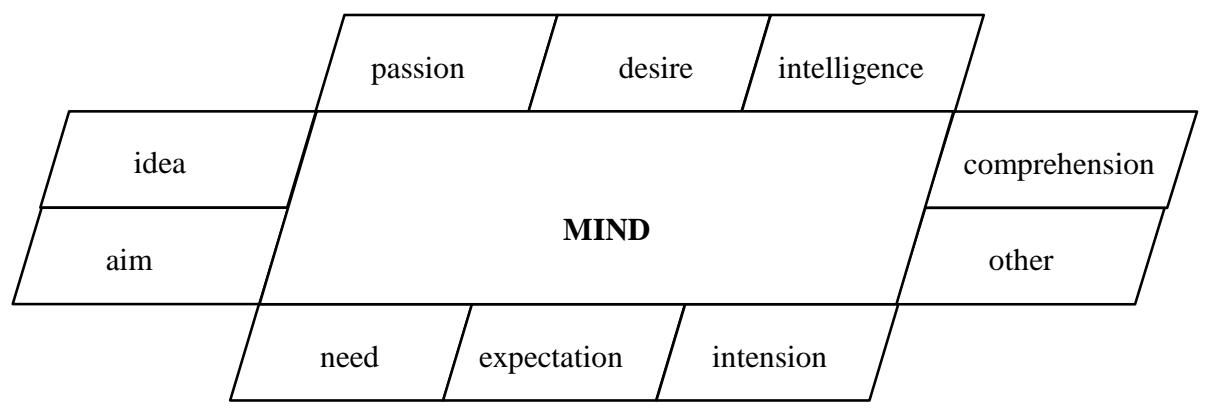

Figure 4. Person's mind.

To have "information" together with the "infrastructure", "fiscal power", "military power" or to have possible use of these four factors regarding the possibilities and abilities, can be helpful to understand how the "functional power levels" change by the related sides, and how their superiority can change due to each other as a functional. Regarding the "information" and "information science" owned by a human and due to the specifications to use these abilities simultaneously, one can define the "functional position levels" of a person for a subject of services by considering one or some or all of the qualities/abilities of "definition", "judgment", "ruling", "admiring", "advice", "education", "commanding", and "sense of justice" together. This indicates that 
a human can go up from the lowest position level of being human to a level of being a person, than to be a group person, to be a group president person, and being a president of groups respectively. It is possible to define these working levels with more sensitive by considering all the subject of services beside taking each of the subject of services separately and one by one. It is possible to consider the information science as a working method, which creates some necessities of the sense of justice through determining and arranging the functional levels for the other subject of services. The functional position levels are more important than functional power levels. The author defined this in other sections, and in other work by considering its possible affects on the continuity of the system and by considering the necessity of people with high functional position levels.

\section{Political Organizing}

There are two important cases for political organizing: (1) Unit structure of a political group/party; (2) Internal organizing of political group/party. With this respect, it is proposed to have a standard unit political group/party structure for each of the political party (Political party, 2015; List of ruling political party, 2015). This new unit structure proposed to supply some benefits: (1) representation of the different parts of the community; (2) representation of the different age levels of the community; (3) representation of equal numbers of man/woman in the unit structure (however levels of a man or a woman will be measured due to the criterions such as success, etc.); (4) representation of married man, married woman, married couple, single man, single woman; (5) representation of the active persons between a minimum age level to a maximum age level; (6) being a member to a political group/party; (7) unit political structure with specific number of person (200 persons are proposed); and (8) Other. After determining the political group/party unit structure as an infrastructure, and after deciding the sense of political construction related with this, it is necessary to make internal organization within the group/party to arrange the working principles for the persons there. With this respect, one can propose to use present political party/group organizing. It is the political organizing which is done by covering the quarters, regions, small towns, villages, counties, provinces in simple manner. It includes chiefs of provinces, etc, and also party assembly, central administration council, etc. This organizing can make a problem in the future in case of the persons related with the politics did not show the necessary sensitivities. There are lots of bad and/or incorrect examples for this. There is a sense, where person related with politics could not come front by his/her political information, possibilities and abilities, but come front with political games. With this respect, a person related with politics who owns a principle to play a game to the same group/party persons, shall be in a behave where he/she can make conflicts to his/her group's friends also to other community persons because of his ethics of politics. One of the necessity for the continuable political administration system defined here is that the present political organizing are including wrongs, absents, injustices, etc. inside, as it is stated in the other parts. On the other hand, internal organizing based on standard active political group/party unit structure proposed so that a person can start to be relate with the politics "actively" starting from 18 years old (at starting age to university) to until some age, for example, 70 years old. For the persons over 70 years old, it is proposed to evaluate, consider the "experiences of such active politic persons" in the other defined units of the system. This type of organizing will guide to people to be a member to the politic group/party, where these persons are counted as persons related with politics, and they will be grouped due to the specifications they are carrying. The political groups/parties that will be form regarding this unit structure, can call as political group/party region council. Together with this new type of political organizing, some of the following benefits shall be obtain; limited number in present organizing, population 
will be transferred to the council structure with linear ratio, participated politics will be increased, a well-informed community will be created, other (defined by the author separately).

\section{Academies}

The politics, politicians and the political administration system itself in general, needs educated persons related with public sector (Public Administration, 2015), private sector and related with "political administration system". In an ideal continuable political administration system, it is necessary to make the all related persons to be educated in the defined subjects of services, more or less. That means politics, politicians should be educated in some manner. While supplying this education through the academies, education schools, one should have a target to have information about the following matters related with each subject of service: (1) information science; (2) name of the subject; (3) importance of the subject; (4) the meaning of the subject; (5) applications of the subject; (6) relations of the subject with other subjects; (7) benefits of the subject; (8) definitions related with the subject; (9) words related with subject; (10) teachings related with subject; (11) present rules, laws, regulations, bulletins; (12) history of the subject; (13) exact meanings of the words related with subject; (14) persons who are under education, teaching regarding the subject; (15) persons who makes teaching regarding the subject; and (16) other. This will be helpful to obtain professional service groups and/or progression of the groups. The author proposed that in each country there should be education schools established regarding the following types, beside modifying the present schools due to these new types: (a) Regarding the public sector: bureaucrat education school, public personnel education school, profession lycees (colleges), politicians education school, universities; (b) regarding the private sector: profession lycees (colleges), universities. With these arrangements, there will be some benefits, such as supplying a politician regarding the needs of the state, supplying a bureaucrat regarding the needs of the state, supplying a public personnel regarding the needs of the state, increasing the meaning and importance of all other education institutions, planned education shall obtained, planned employment shall obtained, and others. It is important to educate, teach the thoughts and senses as "good and/or correct". Also it is important to teach the people with correct information science, so that for example a people should be able to realize the difference between the foxy person and intelligent person. The persons with these specifications principally will serve to correct aims and shall perform the related responsibilities due to information science. Existence of these types of persons, where the author believes there are some persons exist in some countries more or less, is important and necessary for a country or countries' union system because of the following purposes: (i) illuminating the sides correctly; (ii) preventing the sides to make wrong; (iii) preventing the misunderstandings; (iv) supplying good and/or correct education; (v) to have a correct coordination in some subjects; (vi) to make pioneering of some works, (vii) to be able to make the realization correctly regarding the information science in top level; (viii) to be able to solve the possible other problems due to judicious point of view; (ix) to fix the conflicts; and (x) to remove the conflicts permanently, other. A person will learn the theory and application (practice) separately and together through the information science he/she own, and will learn these subjects at suitable age levels. These academies can be "good and/or correct" guide for the people to learn (Economic science, 2015; Educational Science, 2015; Engineering science, 2015; Historic science, 2015; Philosophy, 2015; Philosophy of politics, 2015; Philosophy of religion, 2015; Political Engineering, 2015; Political Science, 2015; Social Engineering, 2015; Social Science, 2015; Governance, 2015; International Relations, 2015) and other "good" disciplines. Each of these disciplines can be "good" starting point to understand different point of views in the 
system, however, it is important to guide some people to have education about the new perspective defined here, which consider continuable/sustainable administrative system that includes every subjects in general manner. The author proposed to teach people the system officially and/or non-officially at the same time and/or through the correct persons, and as necessary part of supplying justice expressed here with three complementary methods.

\section{To Choose and to be Choose}

In general, persons related with politics, and other persons or group persons which can be necessary about each subject of services in the system, can be determine through one or more of the following ways: (1) due to selection directly up to the person: selection of education subject, selection of education school, selection of education place, selection of job/work subject, selection of accommodation place, other; (2) due to selection of the person through other persons: to be choose by administrator, to be choose by the community persons, to be choose by the group persons, to be choose by the public persons; (3) person selection through the system: selection due to system criterions, selection by examination, selection through the success at the education; (4) selection of a person by system and other persons. Here it is important to remember that there are some notices that the present systems are not judicious enough, or the justice system (Social justice, 2015; Law, 2015; others) is not progressed enough, or the systems are not inspected by the judicious persons, or the persons are not judicious enough. Once all the subjects mentioned through this political administration system are considered together, the arrangements proposed by the author will decrease the possibility of mistake in the system that could be done by some person (who choose another person, or person who defines criteria, or person who makes evaluation, or person who defines system), to a minimum with the new defined system. Regarding the political administration system and the related official units considered, possible evaluations of the situations are explained briefly below for the units that could be dutied/choosed due to performance of the system. The criterions can be consider for some other sides as well beside the politics. The author defined the criterions, other correct selection method, approach for other persons, groups, private sector associations related with each of the specific parameters, which are not expressed here with details, in other work. It is important to determine the system criterions for "choosing a person" and for "to be choose by a person". It is necessary to define following types of system criterions for the persons that could be choose, or for making easiness at the person's selection during their works, where the political administration system, other related sides, associations, etc. shall need: (i) defining the system criterion for guiding person to choose; and (ii) determination of the criterions for choosing a person through the system. There are 13 system criterions defined for guiding person to choose. It is necessary to define these criterions with details in case of a selection is directly related with a person or in case of a selection is up to a person. Determination of the criterions for choosing a person through the system is important on the other hand. It will be necessary or required for the persons who are related with politics directly or indirectly, and works at different sectors, to satisfy some of the criterions together or separately regarding the judicious point of view, while they are being choosing, or being dutied or being appointed to a work. It is necessary to define the "definitions related with works" and to define "evaluation criterions" related with these works simultaneously and correctly for making the selection of a person through the system or for making the selection by "system and person". General evaluation criterions that can be consider are; Education criterions, Success criterions, Working criterions, Benefit criterions, Ethic criterions, Selection criterions, others. In a simple sense, "evaluation levels" of a person for a subject can be given as follow (see Figure 5) where it can be correct guide during the examining of the general evaluation criterions. 


\begin{tabular}{|c|c|c|c|c|c|c|c|c|c|c|c|c|c|c|c|c|}
\hline \multirow{2}{*}{ 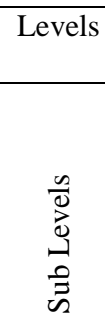 } & \multicolumn{2}{|c|}{$\begin{array}{c}\text { Good and } \\
\text { correct }\end{array}$} & \multicolumn{2}{|c|}{ Correct } & \multicolumn{2}{|c|}{ Good } & \multicolumn{2}{|c|}{$\begin{array}{l}\text { Good and } \\
\text { incorrect }\end{array}$} & \multicolumn{2}{|c|}{$\begin{array}{c}\text { Bad and } \\
\text { correct }\end{array}$} & \multicolumn{2}{|c|}{ Incorrect } & \multicolumn{2}{|c|}{$\mathrm{Bad}$} & \multicolumn{2}{|c|}{$\begin{array}{l}\text { Bad and } \\
\text { incorrect }\end{array}$} \\
\hline & 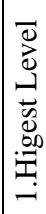 & $\begin{array}{l}\vec{d} \\
\vec{d} \\
\stackrel{d}{d}\end{array}$ & 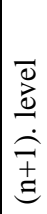 & 总 &  & 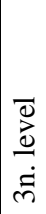 & 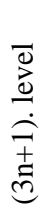 & 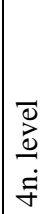 & 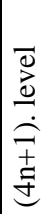 & $\frac{\vec{d}}{\stackrel{d}{\leftrightarrows}}$ & 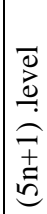 & 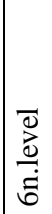 & 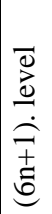 & $\frac{\vec{d}}{\stackrel{0}{d}}$ & 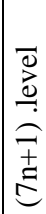 & 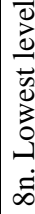 \\
\hline
\end{tabular}

Figure 5. Evaluation levels of a person for a subject

This "evaluation levels" can be taken into consideration for the evaluation of a work/action that could be done by a person alone or together with a group, or together with a community, or together with a country. There is another study of the author, which considers all possible subjects and other matters evaluated together though these "evaluation levels". Here the evaluation levels defined in line-1 of Figure 5 are "necessary and sufficient" for an expert. However, considering the transition between the 8-levels, one may define sub levels, and divide each level to suitable sub levels, which means there will be $(8 \mathrm{x} \mathrm{n})$ levels from highest level to lowest level. It is possible to define these evaluation levels for a subject and in "polar form" or in other "3-Dimensional form (3D)", where it is very important for all of the applications in each block of the general structure of the political administration system for a country gave in Figure 1. These evaluation levels are also very important for sense of justice, and they are called eight-basic senses for evaluation.

\section{Situation Notice}

It is important for each of the association in a country to have a situation notice in the following categories for having an effective data regarding the association or regarding the related associations, units. With this respect, following four cases should consider basically to make situation notice: (1) "Number of humans" in different categories and related with each of the specific parameters (educated, uneducated, retired, less educated, high educated); (2) "Information" about each of the subjects or each of the specific parameters (present information, imported information, etc.); (3) "Infrastructure" (In general it consists the residences, business offices, factories, public buildings, vehicles, tools, equipments and other related hardware, software about all specific parameters, and available in the country or outside the country, or produced in the country or outside the country); and (4) "Costs, fee, expenses" (present monetary sources, fix service costs, variable service costs, employee costs, available natural sources that can convert to real money, infrastructure costs, continuously available sources, etc.). Together with these situation notices, the possibilities and abilities will be able to define. It is obvious that, the system that will supply these data together will make the process easy and increase the productivity.

\section{Service Parameters}

It is possible to call the things that are served by a side to another side or sides, due to the needs within the processes, and through different ways, types, methods as "service". In general, each of the matters which define the service can be expressed as "service parameters". It will be useful to define the service parameters in general during the planning of the services and their realization for making the processes easy, or for making the processes systematic, and also for making the processes easily controllable, improvable. Some 10 of the service parameters are defined and given below, and other ones which are not mentioned here, can be evaluate related with the policies/strategies through the general aims/targets. The proposed service parameters and their 
weights can be configured together with the defined policies/strategies, and through the aims/targets determined.

Kinds of Services. Defined in the previous article. Regarding the sense of justice and the other subjects, the processes that will satisfy one or more of these kind of services simultaneously, shall be "good and correct" processes for the system.

Subjects of Services. Defined in the previous article.

Service Packet. It is possible for the different sides in the system to define the service, content of the service related with the works that they will offer to the other sides through a service packet. With this respect, it is possible to define the service packet by considering the services that could be supply by the political government together with the public associations and regarding the all subject of services. The service packet can be define for other related service providers (such as companies, municipalities, ministries, departments, banks, in general public and private sectors) with more sensitive.

Way of Service. Defined in the previous article. It is important to make planning of the way of services for short, mid and long period, and by considering the needs, aims and other service parameters, and through their weights, priorities. Considering the subjects here and in other Works of the author, it is not correct to deliver "all services" to the private sector or to local administrations in a country. Also, it is not correct to put the public side outside in most of the applications, and put the public side in regulation side only, because of experienced cases of the author and because of this will make conflict with some of the aims and targets.

Service Types. Defined in the previous article.

Work and Employee Definition. During the employment and determination of the needs and costs due to the subjects of services, the author proposed to make classification of the work subjects due to the pairs of "human number-information amount required" as follows: (a) Works that requires lots of human and few amount of information; (b) Works that requires lots of human and lots of information; (c) Works that requires few number of human and lots of information; and (d) Works that requires few number of humans and few amount of information. This simple classification, together with the evaluation of the specific parameters will make easiness at the planning.

Security. It is necessary to propose the following security types together and separately for designing the systems, for realizing the aims and targets, for making the action planning correct, for controlling the possible effective factors and for continuable policies and strategies; (1) security of the infrastructure; (2) security of the information; (3) security of a person; (4) security of the state; (5) security of the world; (6) security of the public association; (7) security of the sources; (8) fiscal security; (9) security of the private association; (10) security of the system; (11) security of the country; (12) security of the groups of countries; and (13) other (security for the subjects of services). When some of these security types are considered together or separately and evaluated accordingly, it will be also necessary to define security application criterions correctly. Also, while providing a high level of security in "information community" some important subjects should be pay attention during the related works, and during the selection of the technologies and during the investments.

Costs, Sources, Budget. During the definition of the system, and during the realization of it through the action planning that considers aims/targets and policies/strategies, it is necessary to define and classify the following subjects correctly: (1) financial sources (internal, external); (2) costs, expenses (for persons, private sector, public associations); (3) budget planning; and (4) budget sensitivity. The planning of a budget can be realize by considering the budget priority subjects defined by the author, together or separately. Regarding the 
proposed planning sensitivity, because of the possible forceful factors, the budget sensitivity proposed can be change due to changes in the policies/strategies and changes in the realization of the planned actions. One can propose to have a budget sensitivity below a given value or between the given internal. The determination of this is one of the parameter that could be consider to define the success of the political administration. This subject is also mentioned in the planning sensitivity part.

Project Planning. During the definition and execution of the projects, it is necessary to give necessary and sufficient information about the basic points of the projects. These basic points are: (i) subject of project; (ii) aims of project; (iii) theoretical basics of project; (iv) importance of the project; (v) benefits of project; (vi) proposed project team; (vii) requirements for the realization of project; (viii) proposed working ways, (ix) research method; (x) research possibilities; (xi) measurement mechanism; (xii) necessary expertise; (xiii) manufacturing processes; (xiv) cost analysis; (xv) co-operation; (xvi) duration; (xvii) budget; and (xviii) project work flow plan.

Quality of Service. The measure of the productivity, performance of the works to be done is quality of service. For the determination of the quality of service, it is necessary to measure quality for the related subject of service, to define the necessary parameters for making these measures, to be able to evaluate measurement/observed data correctly, to obtain the administration of the service quality values and to reach optimum values that could be. With this respect, following three cases are important: (1) measurement/monitoring of the quality of service; (2) evaluation of the quality of service measurements; and (3) administration of quality of service. The measurement method that will be consider due to the subject of service is important for measuring the service quality specially. As a next stage, it is important to consider the correct parameters for measuring the quality of service. In general, it will be useful to make the measurements of the quality of service through the aims/targets for determining and understanding the degree of the success of the policies/strategies. With this point of view, the ways of service quality defined by the author for different sides can be very useful. The measurement of the service quality make necessary to do some evaluations about the comparison of the previous data. This evaluation can make through a ranking or classifying defined from the measured data. Here, ranking parameters should be considered and choosed to reflect the truths. There are some works done by the author about the evaluation of the measurements related with some subjects of services. Today, some evaluation associations defined in some other countries are making evaluations by using the measurements, observations data due to the subject of services, due to operation modules, etc. and by considering the parameters they defined, and as a consequence they are making the ranking. The control and administration of the quality of service is as important as serving the services. The author defined the suitable control and administration system accordingly, that will supply correct and judicious administration.

\section{Possible Problems}

For continuable political administration system, it is necessary to consider past, present and possible future problems of a country, and past, present and possible future problems in other countries in simple manner. The present problems and some possible problems that could be in the future in a world country, which can be related with the political administration, and can effect the aims/targets or delay the aims/targets, or determine the political sense previously for short, mid and long term (see Table 1). 
Table 1

Types of Problems (in Alphabetic Order)

\begin{tabular}{|l|l|l|l|}
\hline Administration & Environment & Infrastructure & Political \\
\hline Agricultural & Financial & Inspection & Religion \\
\hline Border & Geographical & Legal & Security \\
\hline Commercial & Health & Manpower & Stockbreeding \\
\hline Community Values & Historic & Military & Terror \\
\hline Economic & Human rights & Natural sources and Energy & Transportation \\
\hline Education & Industrial, technological & Organized crimes & Other (specific parameters) \\
\hline
\end{tabular}

It will be necessary to continue the possible research about these possible problems inside and outside the country and with memory based. Also, it will be helpful to know these problems to make correct decisions while making planning. Beside the possible problems in the home country, other problems which are lived before or currently exist in similar subjects at the other countries should be known as possible forceful factors, and be considered and evaluated accordingly. Some of the problems are because of the possible aims that could be consider by some politic/non-politic persons to provide superiority which can also be related with the types of problems mentioned above (see Table 2). To be able to make the solution of the past, present and possible future problems of the all countries, continuable administration system and Countries' Union system is defined.

Table 2

Possible Aims that Could Provide Superiority

\begin{tabular}{|l|l|l|}
\hline infrastructure superiority & superiority of the people & superiority of the community \\
\hline superiority of the military power & superiority of law & superiority of the country \\
\hline information superiority & superiority of the ideology & superiority of the ethnic origin \\
\hline superiority of a person & superiority of the money & superiority of the structural group \\
\hline superiority of the region & political superiority & superiority of the politic group \\
\hline superiority of the state & superiority of the social justice & other \\
\hline superiority of the religion & commercial superiority & \\
\hline
\end{tabular}

\section{Aims/Targets}

In general, it is possible to characterize the aims/targets as follows with a real approach: (1) aims/targets for making the necessary actions about the requirements; (2) aims/targets based on solving the problems; (3) aims/targets based on obtaining superiority; (3) aims/targets based on obtaining superiority while making the necessary actions about the requirements; (4) aims/targets based on obtaining superiority while making the solution of the problem; (5) aims/targets based on obtaining superiority while making the necessary actions about the requirements AND solving the problems; and (6) other. Regarding the political administration system defined here and the Countries' Union system, some aims that can be separate and common for related sides are defined with the following groups: (a) Aims about persons; (b) Aims about private Sector; (c) Aims about state control; (d) Aims about other countries; (e) Common aims; and (f) Aims about official/non-official groups. While determining and defining these aims, it will be useful to make classification due to subjects of services and professional interests. Once the aims/targets defined correctly, the next step is to put the related sides into competition in some manner, instead of war, where it is one of the aspects of being a progressed community, or to be able to reach this thought and sense phase. With this respect, possible aims that could provide superiority 
(see Table 2), and possible tools for providing superiority (see Table 3), and possible aims that could solve the types of problems (see Table 1) should be consider. Of course some of the aims gave in Table 2 are "good and/or correct" for continuable political administration system, not all.

Table 3

Possible Tools for Providing Superiority,

\begin{tabular}{|l|l|l|}
\hline person & Service types & Other possible aim or aims \\
\hline subjects of services & Way of services & other \\
\hline kinds of services & Other service parameters & \\
\hline
\end{tabular}

The author evaluated the possibilities about all the groups in the world and defined the possible aims for each of the groups that could be with more details in some other work, to guide them to be a correct part of the continuble administration system, and/or to supply continuity in the system, and/or to not to make any conflict in the system that can cause problem about the continuity/sustainability of the system. In general the author proposed aims/targets as different tools for supplying continuity/sustainability of the defined system, where it means the questions are there and the possible answers to these questions are given here with the ideal political construction, and other subjects.

\section{Other Systems}

With regarding the other systems, experts should consider the followings as important parts of the Continuable (Sustainable) Administrative System: (1) Countries' Union System; (2) Sub Internal Systems; (3) Sub System Groups; (4) System Groups; and (5) System Integration. Countries' Union system is defined in other work (Ramiz, R, forcoming), and it includes every subjects in the world. Sub internal systems proposed to have following sub internal systems for obtaining data related with each of the block parts given in political administration system structure in Figure 1: (a) infrastructure system; (b) information system; (c) administration system; and (d) education/teaching system. Sub system group(s), is a group where an infrastructure system, an information system, an administration system and an education system put together for a block part in the political administration system structure in Figure 1. It is possible to define sub system groups structure as follows for one subject of service or for sub subjects related with the parts: (i) one sub system group, one service packet; (ii) one sub system group, one process module; (iii) more than one sub system group, service packet related with each of the sub system group; (iv) more than one sub system group, process module related with each of the sub system group; (v) more than one sub system group, one service packet; (vi) more than one sub system group, one process module; and (vii) other. System groups are formed together with more than one system defined for one block part in political administration system structure in Figure 1. On the other hand system integration is proposed to be realize in one of the following two different ways given below: (a) integration based on the parameters (see Table 4); (b) integration based on system structure. System integration can be realized "due to the parameters" given below, separately or by taking into consideration these parameters together.

In general, it is possible to define following three types of integration based on system structure, which are related with the political administration system structure given in Figure 1: (1) Sub internal system integration; (2) Sub system group integration; and (3) Systems' integration. 
Table 4

System Integration Parameters (in Alphabetic Order)

\begin{tabular}{|l|l|l|}
\hline Action planning & Limitation caused by the hardware & Service channels \\
\hline Administration types & Limitation caused by the software & Service packet \\
\hline Aims/targets & Persons dutied & Service types \\
\hline Budget & Physical security walls & Sources \\
\hline Costs & Policies/strategies & Subjects of services \\
\hline Criterions & Political construction & System administration \\
\hline Decision making & Possible problems & System structure \\
\hline Imaginary security walls & Process module & Way of services \\
\hline Information science & Quality of service & Work and employee definition \\
\hline Inspection & Security types & Units assigned \\
\hline Kind of services & Sense of justice & Other \\
\hline
\end{tabular}

Note. It is proposed to make the system integration due to these parameters.

\section{Administration of the Systems}

Structure of the political administration system is given in Figure 1. To admire the system, it is necessary to know the followings: (1) way of system administration; and (2) administration types. General things which defines the way of system administration are the parts of the political administration system given in Figure 1, and needed services or service groups related. With these respect, system administration can be propose in two different ways basically: (a) systems which can be control from one center; (b) systems which can be control from more than one center. In general, administration types where the persons or person groups are dutied or faced to realize, can be define as follows: (i) human administration; (ii) country administration; (iii) administration of the countries group; and (iv) administration of the world. The author defined a continuable administration system that considers all of these administration types, also unified them under one framework.

\section{Decision Making}

In general, it will be necessary to make decisions during the realization of the actions that could define together with the administration system considered and realization of the policies/strategies based on these. These decision making can be done through the possible ways given below by considering the other parts of the political administration system: (1) decision making by the humans; (2) decision making of the system; and (3) decision making of humans and system together. With this respect, in both cases where the humans could do decision making alone or together with the system, it will be necessary for the person to consider the following basic points: (a) sense of justice; (b) information science; (c) decision criterions; (d) selection criterions; (e) taking responsibilities; and (f) application criterions. As a simplicity, for understanding the application criterions better, here in general one can consider the decision about "providing" something absolute indispensable, that is related with the two or more systems, two or more structure, etc. The application criterions regarding the application of this decision can be defined as follows (three apples rule): (i) solution that will be done by two sides together; (ii) solution that will be done by one side by giving the monetary equivalent to other side to do it so; and (iii) solution that will be done by one side himself/herself or by forcing the other side by his/her power to do it so. 


\section{Inspection}

It is necessary to make inspection of the proposed new system due to the different inspection ways given below, and together or separately, simultaneously or at different times: (1) inspections by person(s) (includes inspection based on person, group, community); (2) inspection of country (includes inspections for state, for party, for government, for private sector, for public associations, for each specific parameters, for person, for system); (3) inspection of the countries group (includes inspection for person, for country); and (4) inspection of the world (includes inspection for person, for country, for countries group). As it can notice from here, it is necessary to make inspection for each of the ways by considering each way inside other greater coverage way. Here, it is important to make possible to do inspection by the correct persons or groups, and due to the priorities, and through the aims/targets, and by considering that there will be no possibilities to be under forceful effect of the possible internal and/or external sides which the inspector spoken to.

\section{Official Units to be Assign}

It is important to know that there are differences from one country to another in the world in present time, because of the following reason: (a) the services; (b) the subjects of services; (c) the service providers; (d) the administration systems; (e) political systems; and (f) other (see all parts of the continuable political administration system). To remove the differences between the countries and country groups and the worldwide organizations, it is important to consider the following administration systems: (a) administration for a world country; (b) administration for a Country Union (formed by two countries); (c) administration for Countries' Union (formed by more than two countries/two states, such as EU, federations like USA, Russia, Kingdoms like UK, etc.); and (d) administration for the World Countries' Union System (formed for all world countries). Here, it is proposed to have same/similar official units in each of these administration system for obtaining various benefits, such as "easy integration", "easy communication", others (defined by the author). With this respect, following basic units are proposed for "a world country", where the author defined the suitable units for other administration systems in other work so that this type of world country administrations can communicate with the other administration systems easily in good and/or correct way in simple manner. These units are: (1) autonomous (independent) authorities for each of the subjects of services; (2) dependent committees; (3) public associations dependent to the country administration; (4) suitable numbers of ministries; (5) dependent under-secretariat; (6) dependent directorates; (7) territorial administrations; (8) military associations; (9) Inspection, judgment associations; (10) country assembly; (11) presidency (1st president, 2nd president, 3rd president, etc.); (12) country security council; (13) private sector foundations; and (14) others. The author defined the good and/or correct structures for each of these units separately. This will provide same level of representation between the authorities of different world countries. For example, a king in one country shall act as first president, and will have same level with the president of another republican country. These issues, standard unit structures and other related subjects, evaluations are expressed in other work of the author. It is proposed to establish new authorities regarding each of the subjects of services, or if available to make suitable arrangements and/or changes at the present associations and combine them under this new authorities. With these new regulations, there is no need to establish other new departments in a country regarding the units, authorities of other countries. The official units are proposed to be establish and valid for very long period (for example 10,000 years, this example is given to show the sensitivity of the synthesis). Also it is obvious that, with this new (or re-arranged) units, position levels of the units about some of the subjects of services are 
increased comparing with the some present units in some countries. For this type of country administration, or for other types of administrations, it is possible to define Country Presidency System or Countries' Union Presidency System. The author evaluated this for each of the present world country in other work, by considering the ideal political construction, which explained in previous article. People should notice that, this presidency system(s) are "not" like/same with the known presidency system, or semi-presidency system available in the world countries. One may call Country Presidency System as "parliamentary presidency system", which is a "good" but "not correct" definition. The duties, responsibilities of these units, the criterions for choosing or to be assign these units, internal structures of these units, their connections with each other, etc. are defined by the author together with the possible benefits that will supply with these arrangements, or re-constructions, or new establishments.

\section{Persons to be Assign}

It is proposed to assign persons to the units in the administration systems given in previous section. To be able to do this, following persons or groups considered together and simultaneously: (1) five-structural groups; (2) groups about each of the subject of service; (3) noble groups (royal family groups, other related persons, and other honored persons, scientists, ideologues, philosophers, doctors, judges, successful or wisdom persons, etc. are proposed to be in this group); (4) groups about each of the education subject; (5) groups about the field of expertise; (6) persons related with politics; and (7) persons related with the basic official units given in the previous section. All of the persons related with these groups proposed to choose one of the five-structural groups (five to five groups). It is obvious that, the persons to be assign in the each units of a country or in other administration systems defined in the previous section, should be defined by considering the points given in the part "choose and to be choose" of the continuable political administration system of a country. With this type of assignment, it will be possible to provide political government security, security of the associations, security of the persons simultaneously and together with the suitable regulations. It will be possible to realize political process and bureaucratic process in safe and together and separately. Bureaucratic process shall supply the realization of the aims/targets in short, mid or long term, also the system will be continuable. Although one can wish, request or need to assign "one type of ideal person" in military units for example, it is not possible to supply such type of person "all the time" and for "every" period considering the author's experiences, and due to the past, present and possible realistic examples, events, situations. This is also a kind of conflict due to "unique person" definition. This is defined specifically in other work. The above mentioned seven-group/person mentalities will be "good and/or correct" for both military groups, and other politic, non-politic groups to not to face any conflict, dispute, etc. because of internal or external factors. The new defined system proposed to arrange all the possible relations, connections, communications between persons in each different unit in this manner. The possible benefits defined separately.

\section{Action Planning}

There is no doubt that, the planning takes form due to the priorities of the person who makes planning. A system can be configure economically at the responsibility of an economist, and be configured politically at the responsibility of politicians. An action flow regarding the action planning is defined by the author in another work that could be suitable for continuable political administration system. This action flow will make the process systematical on the bases of each unit, also on the bases of higher administration associations. If the aim is to form exact, secure system, people should define the actors (units) that will consider in the planning 
exactly. The good and correct planning, should be defined so that the loads of the systems should be delegated to the units and persons with very sensitive way. This will increase the sensitivity of the planning as well, and supply continuous data flow from or between the units. Although some people can consider some priority targets while make planning, and some other peoples can named these proposed systems with political, social, economics, etc. names, people should not forget that the system defined here and the planning flow will serve to a same and one aim, that is continauble administrative system. In a country, while forming a political administration system, it is necessary to determine one or more action needs by the dutied unit through the service or services planned and/or the needs of that dutied unit. During the determination of the action needs, an action flow is considered. There is an action flow diagram proposed by the author. When the correct data related with the human numbers, amount of the information, infrastructure situation, source amount are obtained as a result of a situation notice, also the planning that could be done through the service parameters, the definition of the system, the way of administration and possible forceful factors are considered, the supply and demand possibilities given in Table 5 below are in question.

Table 5

Supply and Demand Possibilities

\begin{tabular}{|l|l|}
\hline Possible demands & Possible supplies \\
\hline Continuous-constant demand & Continuous-constant supply \\
\hline Constant demand-due to needs & Constant supply-due to needs \\
\hline Periodic-constant demand & Periodic-constant supply \\
\hline Continuous-variable demand & Continuous-variable supply \\
\hline Variable demand-due to needs & Variable supply-due to needs \\
\hline Periodic-variable demand & Periodic-variable supply \\
\hline No demand & Supply available \\
\hline Demand available & No supply \\
\hline
\end{tabular}

These possible situations are determining and effecting the sensitivity of the planning. Ideally, one needs to control the sensitivity of the planning about the defined aims/targets and carry this sensitivity value to constant value or to an interval value. With this respect, a planning sensitivity and related supply-demand possibilities gave in Table 5 can be realize due to a system. This system should be put into a regular configuration to make the system continuable. It will be correct to make the calculations by considering the proposed units and the data that will be taken from these units.

\section{Sense of Justice}

It is possible to make the system continuable/sustainable, make it also permanent and deliver this system from generation to next generation through a sense of justice and the validity parameters together. An ideal system should be judicious in multi ways. This requires that lots of the points given here for the continuable system should be adopted by the community, and at the all related sides. Some of the judicious administration ways which are carried till today by some of the world countries are based on groups and/or community values. With this respect, in general by considering the persons in a country, and their duties, working conditions, interactions with each other, values adopted personally or as a community, and their interaction with the persons in other countries in all these manners, the following ways of justice can be define due to the priorities of the subjects: (1) Justice about a person; (2) religious justice; (3) justice regarding the state; (4) commercial 
justice; (5) justice regarding the country; (6) justice about all subjects of services; and (7) in general, justice about all specific parameters. Justice about a person gave in Table 6 below. The contents of the other ways of justice defined separately by the author.

Table 6

Justice Cases About a Person

\begin{tabular}{|l|l|l|l|}
\hline advice right & human right & public justice & social justice \\
\hline community justice & property justice & religious justice & working justice \\
\hline group justice & legal justice & scientific justice & other \\
\hline
\end{tabular}

The solutions of the problems will be valid for a long period, and could be deliver from generation to next generation through the correct applications of the all of these ways of justice by considering them together for all of the subjects of services. In general sense, the justice can be provided officially and/or non-officially through the following methods: (a) by educating judicious persons; (b) by improving justice system; and (c) by making the system judicious. When the subjects mentioned here are considered, one should obtain the justice through these three methods simultaneously for system administration, system inspection, system improvement, its adaptability, etc. The system defined here is designed so that it contains and satisfies justice simultaneously through these three methods. If one fact rejects the process which forms itself, in some sense it reject itself, and this put forward that the sense of justice is not developed sufficiently. It is important to define what is good, bad, correct, incorrect, and comprehend the already defined correct values, incorrect values in "good and correct" way. It is important to ask and give an answer to the following questions for a person, group, community, state, country, countries group who can be a side to a sense of justice, that why a process is necessary to be realized: (a) sense of justice for a need of a one side? (b) sense of justice for the need of the opposite side ? (c) sense of justice for common need? To obtain complete justice, one should satisfy the justice in all of the points given above. This makes necessary to being judicious during the applications, realizations of the defined policies/strategies. There are two important approaches that could effect the sense of justice due to the subjects: (i) absolute benefit; and (ii) absolute success. The effect of these cases on different subjects, persons, groups, systems, etc. defined by the author separately. In general, related sides can face with the following possible situations due to highest to lowest importance respectively: (1) benefit and success; (2) success; (3) benefit; (4) loss and success; (5) benefit and failure/unsuccessful; (6) loss; (7) failure/unsuccessful; and (8) loss and failure/unsuccessful. Events, subjects may propose based on "to have benefit" and/or "being successful" in general, directly or indirectly. There are interesting examples about the relations between the groups, countries that can show these situations. For example, US Congress expressed in the past years about the Cyprus that, "they supplied ... million USD, to the related persons in the Cyprus island and in the other countries, but they failed, however, they created new millionaires. They also stated that they did not find this result correct". Here the benefits of the USA as a country, is to be able to do this criticize, also beside this to notice that there are still some subjects which they are in learning period, and also there are some values in Turkey, in North Cyprus and in other countries where they did not understand them exactly yet, or some people gave them incorrect information, etc. This understanding, situation notice, is an example that shows the approach, method considered for "benefits and/or success" is incorrect for "continuable/sustainable solution". Thoughts and senses, values, some systems and some other points are each acting/using as a tool, but the "sense of justice" is appearing as a balancing, regulatory, permanent element in some manner. Beside this, some people should 
know that the approach of "win-win", is a pronunciation which is used in the past era, and used specially by or for the undeveloped, poor, hunger, etc. groups, communities, countries. Also, in philosophical manner if each side does not earn 50\%, you can not talk about "win-win", which means the words and this twin (idiom) become meaningul for one possible case only. In this New Era, people should search to find out answer to the question of "whether every sides can obtain the benefit they deserved due to sense of justice". During the application of the sense of justice there are two other elements which are basically important: Esteem and Equivalence. Whether the persons are definer, or administrator or dutied persons, they will need a sense of justice while they are having interactions with other persons. It is important to know that, the sense of justice defined for continuable political administration system is a part of the sense of justice proposed for Countries' Union System that includes all the administration system types mentioned before. In a simple sense, the sense of justice shall be evaluated as "good and correct" if this sense can be supply from smallest unit to biggest unit, and for all related subjects of services, with equal importance. The sensitivity of sense of justice is defined by the author in other work.

\section{Determination of the Policies/Strategies}

It is necessary to determine the policies/strategies to be able to apply and admire the works, action plans, etc. due to a certain program. With this respect following points should be taken into consideration: (1) factors which determines policies/strategies; (2) data considered during the determination of policies/strategies; (3) targets of policies/strategies; (4) policies/strategies; and (5) policy/strategy administration. Factors which determine policies/strategies are in general: persons/citizens of a country, private sectors of a country, the state, the political government in a country, non-official private groups, and persons, units in other countries. On the other hand, data regarding some parts given in the continuable political administration system block diagram (see Figure 1) will be consider during the determination of policies/strategies. However, it is important to define the targets of policies/strategies by considering the person, citizens, private sector, public sector, service parameters, political government, present and possible future problems in a country, community values, supplying benefits to the non-official groups, supplying benefits for other countries. With regarding the above mentioned points, political administration is in a position to develop and put into application the policies/strategies that will satisfy all possible needs of the all related sides simultaneously and in short, mid, long term. While determining policies/strategies, action planning related with all sides should be made correctly, the time period, work flow should be defined suitable and stable. With this respect, possible policies/strategies should cover persons, private sector, public and state control, country, other countries, and common purposes. It is also important how to admire the policies/strategies beside the importance of how they are determined. While doing this, it is necessary to have sufficient information about the related subjects, about the political sense in the country and in other countries, about the aims of the political administration, about the political administration system. In case of these information are owned, it will be necessary to consider the following points together for administration of the policies/strategies: possible problems related with policies/strategies, solution of a problem related with policies/strategies, policy/strategy administration ways, inspection of policies/strategies, crisis and conflict administration, duration/permanency of policies/strategies. In general, it is possible to obtain solution to the problems related with policies/strategies by considering different ways. It is important to provide inspection during the applications of the policies/strategies to be able to understand the productivity and if the decisions are correct or not. One can meet with some crises or conflicts during the 
applications of the policies/strategies because of the information absence, misunderstandings, absent planning, etc. during the determination of the policies/strategies. In general, the duration of the policies/strategies, and their permanency are up to the considerations of the following parameters together, in theory and in application: (i) sense of justice; (ii) legal agreement; (iii) mutual trust; (iv) mutual honesty; (v) mutual sincere; (vi) mutual creativity; (vii) correction degree of the information that forms the policies/strategies; and (viii) conflict in theory and application.

\section{Conclusion}

In this work, 17 other important parts of the continuable political administration system are expressed, defined. With this respect, status of the politic persons and ethics of the politic persons are discussed and it is expressed that person who are related with politics should have necessary and sufficient statue and ethic values defined. It is also shown that, any person whether he/she is politics or not, can act with some abilities he/she has due to his nature, due to his/her available relations, his/her mind characteristics. However, the author noticed that defined person nature, person relations are showing the past, present and possible future capabilities, abilities of any person, and these structures are important for each of the part (block) of the continuable political administration system. There may be some politic/non-politic people who are acting similar, but have socialist, monetarist, populist, liberal or other mentalities to do that action. But it is important to separate these ideologies, or person relations with the mentality that have R-democracy, state control favor, R-centrism and R-over politic principles or in more general manner with the mentality that have correct "sense of justice" to do that similar actions. Although any people can be evaluate due to these characteristics, it is important to consider these characteristics to choose any person, or check if the person(s) who choose other person has a capability (ability) to choose a person in "good and/or correct" way. On the other hand, it is important for any people to "use" these capabilities, abilities in "good and/or correct" way for continuable political administration system, and also for their personal life to have "unique character", and to be successful, and/or to be able to do the given, assigned job correctly. Information science is defined by the author, and considered as an important part of the new system, and also as part of a person nature. It is obvious that, information science will increase the sensitivity, and supply correct control of the system. On the other hand, people with a good and/or correct information science ability, will be able to admire continuable political administration system of a country in "good and/or correct" way. People should notice that, information, together with the infrastructure, fiscal power and military power can be use "bad and/or incorrect" purposes, if the people do not have "information science". There are some evaluations in the literature about the powers of some politic people in their countries or in the world. However, it is important to define good and/or correct functional power levels, and functional position levels for any people, to help the people to not to act with their feelings, desires, etc. only but with realistic abilities, senses, sense of justice where it is important for the solutions of some country specific, region specific, world specific subjects. The author defined that a politic/non-politic people can have good and/or correct functional position in the system with the abilities of "definition", and "judgment" and "ruling" and "admiring" and "advice" and "education" and "commanding" and "information science" and "sense of justice". These abilities are important for the new system, because it shows that person can have a high functional power level but can have low functional position level at the same time. Or can have high functional position level but have low functional power level at the same time. In general it is possible to classify politic/non-politic people due to this perspective, from highest "good and/or 
correct" level to lowest level as follows: (1) person with high functional power level and high functional position level; (2) person with low functional power level and with high functional position level; (3) person with high functional power level and with low functional position level; and (4) person with low functional power level and with low functional position level. This shows that most important thing is to have high functional position level, which also reflects the importance of above mentioned nine-abilities together. In the history there are various examples about these abilities, only some politic/non-politic people be able to have "good" ability(ies), and effected the country controls, or region controls, or worldwide control, however, it could not be long lasting because of the absence of other abilities, or because of one of the functional level is not being "good" enough to continue leadership in some subjects, for long period. There are some philosophers who did some studies for long time ago about head of some empires, but "only" considered the "ruling" abilities only. The author defined these functional levels separately in other study, by considering the judgment of the history of whole world in some manner. On the other hand, the author proposed that for the continuity of a political party, or for the continuity of the political administration system in a world country, it is necessary to make good and/or correct political organizing too. If the unit structure and internal organizing is "bad and/or incorrect", it can cause "bad and/or incorrect" actions within a political party, which means if any political people in any political party can act bad and/or incorrectly in the party where he/she is member, he/she can make a problem during the relations between other groups, or in general can make a problem in the continuable political administration system of a world country. As it is stated by the author, justice can be supplied by three ways simultaneously. One of them is the way of education. So it is necessary to educate judicious persons for the continuity/sustainability of the system. Academies or education schools become important in that manner. It is important also "good and correct" to educate both politic and non-politic people to have ideal political construction mentality, thought and senses, for the continuity/sustainability of the system, which is also supplying correct sense of justice to people and for having correct information society. The author defined the important subjects about the characteristic of the academies that should be. However, to show the importance of the senses, and the importance of evaluation of choosing a person and to be choose by a person, the author analyzed a "person" with four-possible senses, and his "idea" that have value due to four-possible senses together. Then, the author made the evaluation of "person" and "idea" together to decide how to evaluate the "person" and/or his/her "idea" for benefits of the continuable/sustainable system. Of course, here the information about both person and idea assumed to be "correct". The author evaluated and noticed that, possible "good and correct" decision rate of a person who makes the evaluation is nearly $3.69 \%$, where the possibility of "correct" decision rate is nearly $9.54 \%$. On the other hand, possible "good" decision rate is nearly $13.54 \%$, possible "good and incorrect" decision rate is nearly $14.15 \%$, possible "bad and correct" decision rate is nearly $14.46 \%$, and possible "bad and/or incorrect" decision rate is nearly $44.62 \%$, and it is very high. Comparing this, possible "good and/or correct" decision rate is nearly $26.77 \%$. The author noticed that the above mention rates are changing, when the new defined eight-basic senses (RR) considered, and the possible "good and correct" decision rate decreases. These basic senses and their importance explained in other work. Thus, to be able to make sensitive decision, it is necessary to make sensitive evaluations, also to define good and/or correct system criterions. This becomes important upon to the position of the human being in the system as well. To make sensitive evaluation and sensitive decision, one also need to have necessary and sufficient information about all specific parameters), in some manner. People should understand the importance of the eight-basic senses, where they can be consider for sensitive evaluation levels, and for sense of justice, and for 
information science in simple manner. Whether there is a person related with private sector, public sector, or political party, or government, he/she must make situation notice basically for four-cases defined above. The continuity of the system, in some manner, dependent to the service parameters, and how the related people evaluate them, use them, define them. Kind of services, subjects of services, service packet, way of service, service types, work and employee definition, security, costs, sources and budget, project planning, quality of service are most important 10-service parameters that could be consider for the system. Importance of each of this parameter shortly explained above. Also it is shown that these service parameters are indicating the interactive relations between the ideology, services, person nature and others. There are many absences in the most of the world countries about supplying all of these service parameters. On the other hand, for continuable political administration system, it is necessary to consider past, present and possible future problems of a country, and past, present and possible future problems in other countries in simple manner. The author defined the most important ones above. On the other hand, "experienced people" should consider all of the aims/targets together for continuable/sustainable political administration system, although some politic/non-politic person or group can choose one or some of them. Superiority search can be a reason, a result, a competition, a character of a person, however, for continuable administration system, it should be only a case of competition. The author explained some possible aims that could be use to provide superiority, to show how a "bad and/or incorrect" person who can use these aims can effect the continuity/sustainability of the system in bad and/or incorrect way. The author defined worldwide continuable administrative system, where a continuable political administration system for a country is one part of it, and proposed to have connection with it under the definition of "other systems" in the block diagram in Figure 1. Thus, a continuable political administration system can work separately and together with the continuable administration system defined by the author. With this respect, it is important to "integrate" all systems to each other through the integration parameters defined. It is important to have good and/or correct administration for the system. Thus, person nature and system together become important. Person should have good and/or correct "sense of justice" and "Information Science" and other seven abilities in any case. The administration of the system becomes more important when: (i) person is good and/or correct and system is good and/or correct; (ii) person is good and/or correct and system is bad and/or incorrect; (iii) person is bad and/or incorrect and system is good and/or correct; and (iv) person is bad and/or incorrect and system is bad and/or incorrect, in simple manner. Decision making is important part of the system too. When the following cases considered together, "experienced people" can realize when to use these cases and for what to use them: (1) decision making by the humans; (2) decision making of the system; and (3) decision making of humans and system together. On the other hand, it is necessary to make inspection of the proposed new system and the related sides due to the different inspection ways and together or separately, simultaneously or at different times. Beside this, the author defined new official units to be assign for continuable political administration system for a world country by considering the synthesis, both theoretical and experienced cases. Some of these units are completely new, some others are modified, some others are re-constructed in some manner. Here, it is proposed to have same/similar official units in each of the administration system for obtaining various benefits, such as "easy integration", "easy communication", others (defined by the author). This will provide same level of representation between the authorities of different world countries. For example, a king in one country shall act as first president, and will have same level with the president of another republican country. For this type of country administration, or for other types of administrations, it is possible to define Country Presidency System or Countries' Union 
Presidency System. The author evaluated this for each of the present world country in other work, by considering the ideal political construction, which explained in previous article. People should notice that, these presidency systems are not like the known presidency system, or semi-presidency system available in the some world countries. On the other hand, persons to be assign to these units should have some criterions. The author proposed seven-types of person/group that should be consider for these purposes. It is obvious that, the persons to be assign in the each units of a country or in other administration systems defined in the previous section, should be defined by considering the points given in the part "choose and to be choose" of the continuable political administration system of a country. There is no doubt that, the planning takes form due to the priorities of the person who makes planning. A system can be configure economically at the responsibility of an economist, and be configured politically at the responsibility of politicians. An action flow regarding the action planning is defined by the author in another work that could be suitable for continuable political administration system, by considering senses of justice. It is important to consider all supply and demand possibilities for action planning too. These possible situations are determining and effecting the sensitivity of the planning, and can be extended and make applicable to many subjects of services, to guide the people to understand why some subjects can control completely, why some subjects can control partly in realistic manner. The author noticed that, some people proposed some ideologies, such as free market, where the related sides ask to be set free any companies, association to offer anything they want, and ask to be competition due to cost, quality, usability, characteristic, performance, etc. which can force some people to consider for example to use some of superiority parameters. This can be "good" in some manner, but it is not "correct", because it is showing that some people could not be able to manage that subject, in simple manner. The ideal political construction includes the answers to all questions in that manner. It is possible to make the system continuable, make it also permanent and deliver this system from generation to next generation through a sense of justice and the validity parameters together. The author defined seven-ways of justice to supply sense of justice for all related parts of the system. In general sense, the justice can be provided officially and/or non-officially through the following methods: (a) by educating judicious persons; (b) by improving justice system; and (c) by making the system judicious. The system defined here is designed so that it contains and satisfies justice simultaneously through these three methods. Beside this, it is important to make determination of the policies/strategies as complementary part of the system by considering the other block subjects. There are mainly 17 languages as it is given below to define, explain, express the subjects. However, it is important if each of these languages includes same sense of justice, and use to express the same senses owned: (1) academic language; (2) commercial language; (3) diplomatic language; (4) English language; (5) expert language; (6) friendly language; (7) ideological language; (8) lawful language; (9) military language; (10) national language; (11) non-official language; (12) official language; (13) philosophical language; (14) political language; (15) religious language; (16) scientific language; and (17) social language (in alphabetic order). Since this work is defined as result of the synthesis of the author (based on both theoretical and experienced information), some people should also understand that as result of the synthesis following cases are inevitably applied by the author: (i) to eliminate some subjects; (ii) to unify some subjects; (iii) to modify some subjects; (iv) to unite some subjects in upper phase; (v) to separate some subjects; (vi) to define all subjects under one framework; (vii) to integrate all subjects; (viii) to define new subjects; (viii) to re-define some subjects; (ix) to remove some subjects but put new subjects instead immediately; (x) to add some subjects; (xi) to keep (protect) some subjects; (xii) to propose progression for all subjects; (xiii) to change the priority of some subjects; (xiv) revolution; (xv) to 
re-construct; (xvi) judgment; (xvii) to train; (xviii) to educate; (xix) to put rules; (xx) to consider common subjects; (xxi) to improve values of some subjects; (xxii) to fix some subjects; (xxiii) to consider transition for some subjects, (xxiv) to balance some subjects; (xxv) to have some waving about some subjects; (xxvi) to converge to some subjects; and (xxvii) others. With these respect, all the Religion-X, all the Ideology-Y, all the Group- $Z$ are considered and integrated to the new system with this perspective in simple manner. There are no subjects that are leaved open ended due to this perspective. The system defined here is a unique system which collects past, present and all other types of possible future arrangements, under one framework through new defined ideal values and with the five-structural groups (five to five sub groups) connected with them. The sensitive evaluation, perspective of these structural groups, and the good, bad, correct, incorrect sides of integrated groups are discussed in other work with more details. With this respect, it is possible to say that, for example, for most of the subjects, Kemalism (Atatürkism) is more progressed than Communism, Socialism in simple manner. However, (new) structural groups defined in Table 5 and Table 6 of the first article (Ramiz, 2015) among the five to five sub groups are more progressed than these integrated political groups and all other political groups. The author proposed that, "some" of the administrators, commanders, country presidents, doctors, editors, experts, first aid persons, ideologues, judges, lecturers, managers, philosophers, politics, religious leaders, scientists, etc. (in alphabetic order) will be in some of these (new) groups given in Table 5 and Table 6. This is proposed because of the missions, duties, sense of justice, ethic promises, etc. they should have due to the definitions, laws, rules about their disciplines. To bring to an end, the new continuable political administration system is defined here for a world country, and this system is necessary for a continuable administration in a country, but not sufficient to obtain continuity/sustainability in the world, also a Countries' Union System, which arranges the relations between the other countries, other groups is also necessary.

\section{References (continued)}

Economic Science. (2015, October). In Wikipedia. Retrieved from https://en.wikipedia.org/wiki/Economic_science Educational Science. (2015, October). In Wikipedia. Retrieved from https://en.wikipedia.org/wiki/Educational_science Engineering Science. (2015, October). In Wikipedia. Retrieved from https://en.wikipedia.org/wiki/Engineering_science Ethnic Groups. (2015, October). In Wikipedia. Retrieved from https://en.wikipedia.org/wiki/List_of_contemporary_ethnic_groups

Ethnic Groups. (n.d.). The World Factbook. Retrieved from https://www.cia.gov/library/publications/the-world-factbook /fields/2075.html

Governance. (2015, October). In Wikipedia. Retrieved from https://en.wikipedia.org/wiki/Governance

Historical Science. (2015, October). In Wikipedia. Retrieved from https://en.wikipedia.org/wiki/Historical_science

Ideology. (2015, October). In Wikipedia. Retrieved from https://en.wikipedia.org/wiki/Ideology

International Relations. (2015, October). In Wikipedia. Retrieved from https://en.wikipedia.org/wiki/International_relations

Law. (2015, October). In Wikipedia. Retrieved from https://en.wikipedia.org/wiki/Law

List of Religions. (2015, October). In Wikipedia. Retrieved from https://en.wikipedia.org/wiki/List_of_religions_and_spiritual_ traditions

List of ruling political parties by country. (2015, October). In Wikipedia. Retrieved from https://en.wikipedia.org/wiki/List_of_ political_parties_by_country

Philosophy. (2015, October). In Wikipedia. Retrieved from https://en.wikipedia.org/wiki/Philosophy

Philosophy of Politics. (2015, October). In Wikipedia. Retrieved from https://en.wikipedia.org/wiki/Philosophy_of_Politics

Philosophy of Religion. (2015, October). In Wikipedia. Retrieved from https://en.wikipedia.org/wiki/Philosophy_of_religion

Political Engineering. (2015, October). In Wikipedia. Retrieved from https://en.wikipedia.org/wiki/Political_engineering

Political Ideologies. (2015, October). In Wikipedia. Retrieved from https://en.wikipedia.org/wiki/Political_ideology

Political Party. (2015, October). In Wikipedia. Retrieved from https://en.wikipedia.org/wiki/Political_party

Political Science. (2015, October). In Wikipedia. Retrieved from https://en.wikipedia.org/wiki/Political_science 
Political Spectrum. (2015, October). In Wikipedia. Retrieved from https://en.wikipedia.org/wiki/Political_spectrum Political Systems. (2015, October). In Wikipedia. Retrieved from https://en.wikipedia.org/wiki/Political_system Public Administration. (2015, October). In Wikipedia. Retrieved from https://en.wikipedia.org/wiki/Political_administration Religion. (2015, October). In Wikipedia. Retrieved from https://en.wikipedia.org/wiki/Religions

Ramiz, R. (2015). A continuable political administration system for world countries-I. International Relations and Diplomacy, $3(9), 609-624$.

Social Engineering. (2015, October). In Wikipedia. Retrieved from https://en.wikipedia.org/wiki/Social_engineering_(politics) Social Justice. (2015, October). In Wikipedia. Retrieved from https://en.wikipedia.org/wiki/Social_justice

Social Science. (2015, October). In Wikipedia. Retrieved from https://en.wikipedia.org/wiki/Social_science 